\title{
SCIDiC
}

International Journal of Dentistry and Oral Science (IJDOS)

ISSN: $2377-8075$

\section{Preference Of Calcium Biosilicate Cements Used By Dental Students For Treatment Of Immature Non -Vital Permanent Teeth - An Institutional Based Retrospective Study}

Research Article

Inchara. $\mathrm{R}^{1}$, Mebin George Mathew ${ }^{2 *}$, Subhashree. $\mathrm{R}^{3}$

${ }^{1}$ Department of Pediatric and Preventive Dentistry, Saveetha Dental College And Hospitals, Saveetha Institute of Medical And Technical Sciences, Saveetha University, Chennai, India.

${ }^{2}$ Senior Lecturer, Department of Pediatric and Preventive Dentistry, Saveetha Dental College And Hospitals, Saveetha Institute of Medical And Technical Sciences, Saveetha University, Chennai, India.

${ }^{3}$ Senior Lecturer, Department of Prosthodontics, Saveetha Dental College and Hospitals, Saveetha Institute of Medical and Technical Sciences, Saveetha University, Chennai, India.

\section{Abstract}

Objective: This study was undertaken to evaluate the preference of calcium silicate cements for the treatment of immature permanent non vital teeth in a dental college.

Materials and Method: Retrospective data collected from June 2019 to April 2020 was obtained from pediatric dental patients visiting private Dental College. Data was analysed using SPSS version 20.0 with chi - square test.19 patients with immature non vital permanent teeth received treatment of which $16(84.21 \%)$ were males and the remaining $3(15.78 \%)$ were females $(\mathrm{P}<0.001)$.

Results: The most affected age group was 13 year olds $(21 \%)$. Right permanent central incisor was the most commonly affected tooth.MTA was found to be the preferred material of choice compared to bioaggregate cements. There was a statistically significant difference between both materials $(\mathrm{P}<0.001)$.

Conclusion: Within the limitations of the study, it can be concluded that MTA is the most preferred calcium biosilicate cement used by dental students for the treatment of immature non vital permanent teeth.

Clinical significance: Calcium biosilicate cements are biocompatible dental materials which have improved mechanical properties and the added advantage of bioactivity. The use of these cements has allowed clinicians to achieve excellent results in the treatment of immature non vital permanent teeth with shorter treatment time.

Keywords: Apexification; Bioaggregate Cements; Biodentine; Immature Non-Vital Tooth; MTA.

\section{Introduction}

Dental injuries are commonly seen with children aged between 6-12 years [1-3]. These children have permanent anteriors which are at various stages of development. These injuries often lead to pulpal necrosis which in often results in incomplete root development with thin dentine walls, funnel-shaped canal with an open apex $[4,5]$. Management of such cases is a significant challenge for the clinician due to lack of adequate apical constriction and presence of thin dentin walls which can easily fracture [6-8]. Tra- ditionally, apexification has been used for the treatment of such teeth using calcium hydroxide $(\mathrm{CH})[9,10]$.

Structurally strengthening non vital immature teeth has received a great deal of attention and different materials and techniques have been examined $[11,12]$. The use of $\mathrm{CH}$ for apexification is questionable these days due to long treatment and doubtful outcomes. The effect that a long-term application of $\mathrm{CH}$ has on the structural integrity of the root dentin has been investigated [13].

The development of mineral trioxide aggregate (MTA) has led to

*Corresponding Author:

Mebin George Mathew, M.D.S,

Senior Lecturer, Department of Pediatric and Preventive Dentistry, Saveetha Dental College And Hospitals, Saveetha Institute of Medical And Technical Sciences, Saveetha University, Chennai, India.

Tel: +91 8951748659

E-mail: mebingeorgem.sdc@saveetha.com

Received: January 12, 2021

Accepted: January 22, 2021

Published: January 29, 2021

Citation: Inchara. R, Mebin George Mathew, Subhashree. R. Preference Of Calcium Biosilicate Cements Used By Dental Students For Treatment Of Immature Non -Vital Permanent Teeth - An Institutional Based Retrospective Study. Int J Dentistry Oral Sci. 2021;8(1):1451-1454. doi: http://dx.doi.org/10.19070/2377-8075-21000289

Copyright: Mebin George Mathew 2021 . This is an open-access article distributed under the terms of the Creative Commons Attribution License, which permits unrestricted use, distribution and reproduction in any medium, provided the original author and source are credited. 
shorter treatment time with more predictable success. Originally introduced as a root end filling, MTA's ability to promote formation of hard tissue presents the potential of a biological seal of cementum over the material which has made it the material of choice for treatment of immature permanent teeth for the past two decades [14].

Biodentine is a new calcium silicate cement which was introduced in 2012. With a setting time of 12 minutes, Biodentine has an added advantage of better mechanical properties and lower risk of bacterial contamination compared to MTA and requires only a single step to use $[13,14]$. Till date, there has been no study which has assessed the preference of calcium silicate cements for the treatment of immature permanent non vital teeth. Hence this study is undertaken to evaluate the preference of bio calcium silicate cement used by dental students for treatment of immature non-vital permanent teeth.

\section{Materials and Methods}

The present study was carried out in the Department of Pediatric and Preventive dentistry after receiving ethical clearance from the Institutional Review Board of the institution. SDC/ SIHEC/2020/DIASDATA/0619-0320. Only pediatric dental patients who were younger than 18 years of age and had immature non vital permanent teeth were included in the study. Patients who were older than 18 years, mature non vital permanent teeth and those with systemic diseases were excluded from the study.

Data was retrospectively collected from the case records of patients who visited the Department of Pediatric and Preventive Dentistry from June 2019 to March 2020 at private Dental Col- lege and Hospital. Out of the 55 patients whose data was obtained, only 19 who fulfilled the inclusion and exclusion criteria were included in the study. Data was statistically analysedusing SPSS version 20.0. The chi square test values were used to compare data and distributions at 0.05 level of statistical significance.

\section{Results}

A total of 19 patients were included in the study which consisted of 16 boys (84.21) and 3 girls $(15.78 \%)$. The most affected age group was 13 year olds. The age and gender distribution is shown in. The most affected tooth was $11(47.36 \%)$ followed by $21(42.1 \%) .31$ and 41 were least affected (5.26\% each). The distribution of treated immature non vital permanent teeth according to age groups. There was a statistically significant difference in the preference of biosilicate cement used. MTA was the most preferred compared to other bioaggregatematerials $(\mathrm{P}=0.16$ ). Bioaggregate was used only in the age group 14- 16 years. ( Figure 1). Figure 2 shows the gender and biosilicate cement correlation. Of the 3 girl patients, 2 received MTA and one received bioaggregate. 11 boys received MTA whereas the remaining 5 received bioaggregate materials ( $\mathrm{P}=0.943$ ).

\section{Discussion}

The treatment of immature teeth has been seen as a clinically difficult scenario. Immature non vital teeth permanent teeth present with difficulties that are not encountered when teeth in adult patients [14]. The apical diameter of the canal is often larger than the coronal diameter, rendering mechanical root canal debridement difficult [15]. The lack of an apical constriction makes canal obturation in all dimensions difficult. The thin walls of the tooth

Figure 1. Bar graph depicts the Correlation between age and biosilicatecement used. X-axis denotes age and Y-axis denotes the number of patients treated with MTA and bioaggregate materials. The blue colour denotes MTA and the red colour denotes Bioaggregate material. Graph 1 shows that in the age group of 8-10 years(21.05\%) and 11-13 years(31.58\%) MTA was the preferred bio calcium silicate cement. Bioaggregatematerial(26.32\%) was more preferred in patients above the age of 14 years. Using the Chi square test $p$ value $=0.16>0.005$ is not statistically significant.

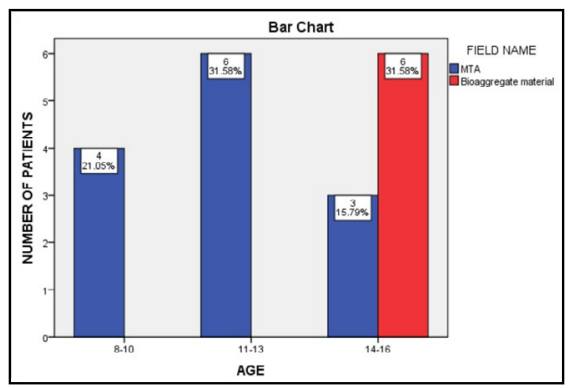

Figure 2. Bar graph depicts the Correlation between gender and biosilicate cement used. X-axis denotes Gender and

Y-axis denotes the number of patients treated with MTA and bioaggregate materials. The blue colour denotes MTA and red colour denotes bioaggregate material. Graph 2 shows that MTA was the most preferred biocalcium cement among both Boys $(57.89 \%)$ and girls (10.53\%). Using the Chi square test $\mathrm{p}$ value $=0.943>0.005$ is not statistically significant.

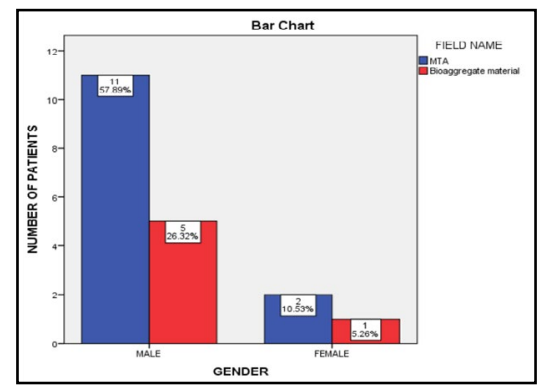


have a high chance to fracture making treatment difficult. Historically, techniques for the management of non-vital immature teeth have included custom fitting gutta-percha cones as the filling material without a prior apexification procedure [16].

The first description of the use of $\mathrm{CH}$ as an agent to induce apical closure was in 1953. CH apexification results in deposition of calcified tissue adjacent to the filling material. One $\mathrm{CH}$ is placed; it may or may not result in the closure of apex often leading to multiple visits. The time taken for formation of a hard tissue-barrier with regard to $\mathrm{CH}$, ranges 6-18 months. This prolonged treatment period becomes difficult for both patient and practitioner. $\mathrm{CH}$ affects the mechanical properties of dentin when used for a longer period of time rendering the tooth susceptible to fracture [17].

MTA has become popular in the past few decades as it produces significantly better hard tissue formation than $\mathrm{CH}$ and also favours in the formation of bone and periodontium [18]. The clinical success of MTA apexification has made it the material of choice for most clinicians. However it is difficult to place in a wide apical area, is very expensive and requires two appointments to complete. To overcome these disadvantages, Biodentine was introduced as the ultimate dentin substitute [19]. Biodentine has quicker setting time and high $\mathrm{pH}$ which results in the release of calcium and silicon ions which stimulates mineralization imparting a better seal [20].

In the present study, the results showed that MTA was most commonly used in patients below the age of 15 who were predominantly males. This could be due to the fact that MTA would have been the most easily available material in an institutional setting. Another reason could be that since bioaggregate materials set quickly, they would require cooperation from the side of the patient and would make MTA an easier choice. The male predominance in our study could be due to the active participation in contact sports.

Endodontically treated immature teeth are more susceptible to root fracture because of its thin dental wall [21]. Studies have shown that MTA reduced the fracture resistance of the dentin by $33 \%$ [22]. Subhash et al found that biodentine did not have satisfactory fracture resistance [23]. Elnaghy contradicted staging MTA and Biodentine have no difference in fracture resistance [24].

MTA has been used for over 20 years by dentists world over and is being accepted as the material of choice [25]. However new calciumbiosilicate cements such as Biodentine and bioaggregate have been introduced which compensate for many of the disadvantages of MTA. Research with these materials is still in the nascent stages and the data available is scarce [26].

Our study had limitations such as being a single centred study with a small sample size. However long term follow up of these patients will allow us to know the clinical success of these materials and help in better clinical decision making.

\section{Conclusion}

Within the limitations of our study we conclude that MTA was the preferred calcium biosilicate cement of choice for treatment of immature permanent teeth. However new calcium biosilicate cements have been introduced in the recent years and only long term studies will help us understand which material will be the best for the treatment of immature non vital permanent teeth.

\section{Clinical Significance}

Calcium biosilicate cements are biocompatible dental materials which have improved mechanical properties and the added advantage of bioactivity. The use of these cements has allowed clinicians to achieve excellent results in the treatment of immature non vital permanent teeth with shorter treatment time.

\section{Acknowledgement}

We would like to acknowledge the Department of Research and IT, Saveetha dental college and Hospitals, Saveetha Institute of Medical and Technical Sciences for their help during the study.

\section{References}

[1]. Parirokh M, Torabinejad M. Mineral trioxide aggregate: a comprehensive literature review--Part III: Clinical applications, drawbacks, and mechanism of action. J Endod. 2010 Mar;36(3):400-13.Pubmed PMID: 20171353.

[2]. Govindaraju L, Gurunathan D. Effectiveness of Chewable Tooth Brush in Children-A Prospective Clinical Study. J ClinDiagn Res. 2017 Mar;11(3):ZC31-ZC34.Pubmed PMID: 28511505.

[3]. Gurunathan D, Shanmugaavel AK. Dental neglect among children in Chennai. J Indian Soc Pedod Prev Dent. 2016 Oct 1;34(4):364-369.

[4]. Brito-Júnior M, Pereira RD, Veríssimo C, Soares CJ, Faria-e-Silva AL, Camilo CC, et al. Fracture resistance and stress distribution of simulated immature teeth after apexification with mineral trioxide aggregate. IntEndod J. 2014 Oct;47(10):958-66.Pubmed PMID: 24386969.

[5]. Nair M, Jeevanandan G, Vignesh R, Subramanian EM. Comparative evaluation of post-operative pain after pulpectomy with k-files, kedo-s files and mtwo files in deciduous molars-a randomized clinical trial. Braz. Dent. Sci. 2018 Oct 24;21(4):411-7.

[6]. Ravikumar D, Jeevanandan G, Subramanian EMG. Evaluation of knowledge among general dentists in treatment of traumatic injuries in primary teeth: A cross-sectional questionnaire study. Eur J Dent. 2017 AprJun;11(2):232-237.Pubmed PMID: 28729799.

[7]. Govindaraju L, Jeevanandan G, Subramanian E. Clinical Evaluation of Quality of Obturation and Instrumentation Time using Two Modified Rotary File Systems with Manual Instrumentation in Primary Teeth. J ClinDiagn Res. 2017 Sep;11(9):ZC55-ZC58.Pubmed PMID: 29207834.

[8]. Jeevanandan G. Kedo-S Paediatric Rotary Files for Root Canal Preparation in Primary Teeth - Case Report. J ClinDiagn Res. 2017 Mar;11(3):ZR03ZR05.Pubmed PMID: 28511532.

[9]. Subramanyam D, Gurunathan D, Gaayathri R, Vishnu Priya V. Comparative evaluation of salivary malondialdehyde levels as a marker of lipid peroxidation in early childhood caries. Eur J Dent. 2018 Jan-Mar;12(1):67-70. Pubmed PMID: 29657527.

[10]. Govindaraju L, Jeevanandan G, Subramanian EMG. Comparison of quality of obturation and instrumentation time using hand files and two rotary file systems in primary molars: A single-blinded randomized controlled trial. Eur J Dent. 2017 Jul-Sep;11(3):376-379.Pubmed PMID: 28932150.

[11]. Ramakrishnan M, Bhurki M. Fluoride, Fluoridated Toothpaste Efficacy And Its Safety In Children-Review. Int. J. Pharm. Sci. Res. 2018 Oct $1 ; 10(04): 109-14$.

[12]. Somasundaram S, Ravi K, Rajapandian K, Gurunathan D. Fluoride Content of Bottled Drinking Water in Chennai, Tamilnadu. J ClinDiagn Res. 2015 Oct;9(10):ZC32-4.Pubmed PMID: 26557612.

[13]. Christabel SL, Gurunathan D. Prevalence of type of frenal attachment and morphology of frenum in children, Chennai, Tamil Nadu. World J Dent. 2015 Oct;6(4):203-7.

[14]. Govindaraju L, Jeevanandan G, Subramanian EM. Knowledge and practice of rotary instrumentation in primary teeth among indian dentists: A questionnaire survey. J Int Oral Health. 2017 Mar 1;9(2):45.

[15]. Jeevanandan G, Govindaraju L. Clinical comparison of Kedo-S paediatric rotary files vs manual instrumentation for root canal preparation in primary molars: a double blinded randomised clinical trial. Eur Arch Paediatr Dent. 
2018 Aug;19(4):273-278.Pubmed PMID: 30003514.

[16]. Panchal V, Jeevanandan G, Subramanian E. Comparison of instrumentation time and obturation quality between hand $\mathrm{K}$-file, $\mathrm{H}$-files, and rotary Kedo$S$ in root canal treatment of primary teeth: A randomized controlled trial. J Indian SocPedodPrev Dent. 2019 Jan-Mar;37(1):75-79.Pubmed PMID: 30804311.

[17]. Packiri S, Gurunathan D, Selvarasu K. Management of paediatric oral ranula: a systematic review. J Clin Diagn Res. 2017 Sep;11(9):ZE06-ZE09.

[18]. Zhu L, Yang J, Zhang J, Peng B. A comparative study of BioAggregate and ProRoot MTA on adhesion, migration, and attachment of human dental pulp cells. J Endod. 2014 Aug;40(8):1118-23.Pubmed PMID: 25069918.

[19]. Cauwels RG, Pieters IY, Martens LC, Verbeeck RM. Fracture resistance and reinforcement of immature roots with guttapercha, mineral trioxide aggregate and calcium phosphate bone cement: a standardized in vitro model. Dent Traumatol. 2010 Apr;26(2):137-42.Pubmed PMID: 20141522.

[20]. Han L, Okiji T. Uptake of calcium and silicon released from calcium silicate-based endodontic materials into root canal dentine. IntEndod J. 2011 Dec;44(12):1081-7.Pubmed PMID: 21777256.

[21]. Tay FR, Loushine RJ, Lambrechts P, Weller RN, Pashleyss DH. Geometric factors affecting dentin bonding in root canals: a theoretical modeling ap- proach. J Endod. 2005 Aug;31(8):584-9.Pubmed PMID: 16044041.

[22]. White JD, Lacefield WR, Chavers LS, Eleazer PD. The effect of three commonly used endodontic materials on the strength and hardness of root dentin. J Endod. 2002 Dec;28(12):828-30.Pubmed PMID: 12489652.

[23]. Subash D, Shoba K, Aman S, Bharkavi SKI, Nimmi V, Abhilash R. Fracture Resistance of Endodontically Treated Teeth Restored with Biodentine, Resin Modified GIC and Hybrid Composite Resin as a Core Material. J ClinDiagn Res. 2017 Sep;11(9):ZC68-ZC70.Pubmed PMID: 29207837.

[24]. Elnaghy AM, Elsaka SE. Fracture resistance of simulated immature teeth filled with Biodentine and white mineral trioxide aggregate - an in vitro study. Dent Traumatol. 2016 Apr;32(2):116-20.Pubmed PMID: 26381857.

[25]. Nazzal H, Tong H, Nixon P, Duggal M. Regenerative endodontic therapy for managing immature non-vital teeth: a national survey of UK paediatric dental specialists and trainees. Br Dent J. 2018 Feb 23;224(4):247-254.Pubmed PMID: 29472688.

[26]. Asgary S, Eghbal MJ, Parirokh M, Ghoddusi J, Kheirieh S, Brink F. Comparison of mineral trioxide aggregate's composition with Portland cements and a new endodontic cement. J Endod. 2009 Feb 1;35(2):243-50. 